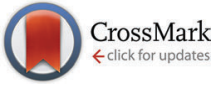

Cite this: Chem. Commun., 2016, 52, 3127

Received 3rd November 2015, Accepted 6th January 2016

DOI: $10.1039 / \mathrm{c5cc09110a}$

www.rsc.org/chemcomm

\section{Phosphorescent columnar hybrid materials containing polyionic inorganic nanoclusters $\uparrow$}

\author{
S. K. Nayak, ${ }^{a}$ M. Amela-Cortes, ${ }^{a}$ M. M. Neidhardt, ${ }^{b}$ S. Beardsworth, ${ }^{b}$ J. Kirres, ${ }^{b}$ \\ M. Mansueto, ${ }^{b}$ S. Cordier, ${ }^{a}$ S. Laschat ${ }^{\star b}$ and Y. Molard*a
}

\begin{abstract}
The ternary polyionic inorganic compound $\mathrm{Cs}_{2} \mathrm{Mo}_{6} \mathrm{Br}_{14}$ and 18-crown-6 ethers bearing two o-terphenyl units have been combined to design phosphorescent columnar liquid crystalline hybrid materials. The obtained host-guest complexes are very stable even at high temperatures. Depending on their surrounding atmosphere, these hybrids switch reversibly from a high-to-low luminescence state and show a very stable emission intensity up to $140{ }^{\circ} \mathrm{C}$.
\end{abstract}

Columnar liquid crystals (CLCs) have attracted much interest in materials chemistry since 1977 when Chandrasekhar discovered them during his studies of discotic benzene hexaalkanoates. ${ }^{1}$ These materials self-organise spontaneously usually into columns, show self-healing properties and have been shown to be useful in the design of many devices including photovoltaic solar cells, field effect transistors, one dimensional conductors and light emitting diodes. ${ }^{2}$ It was also found that non-disk-shaped molecules can form columnar mesophases. Recently, they were also used to organise small amounts of bulky inorganic components such as gold nanoparticles, ${ }^{3}$ gold nanorods, ${ }^{4}$ or quantum dots over a wide range. ${ }^{5}$ Addition of new functionalities to CLCs, e.g., phosphorescence, appears then, to be particularly appealing in terms of application prospects but still remains very challenging in terms of LC phase or emission stability. We present herein the first hybrid CLC containing up to $34.4 \mathrm{wt} \%$ of polyionic, bulky, transition metal cluster (TMC) salts. TMCs are aggregates of metal atoms linked by metal-metal bonds. ${ }^{6}$ In particular, octahedral TMC based compounds of the general formula $\mathrm{A}_{n} \mathrm{M}_{6} \mathrm{X}_{8}^{\mathrm{i}} \mathrm{X}_{6}^{\mathrm{a}}$ where $\mathrm{A}=$ alkali cation, $\mathrm{M}=\mathrm{Mo}$ or Re, $\mathrm{X}^{\mathrm{i}}=$ halogen

\footnotetext{
${ }^{a}$ Université de Rennes 1 - CNRS UMR 6226 "Institut des Sciences Chimiques de Rennes", Campus de Beaulieu, CS 74205, 35042 Rennes Cedex, France. E-mail: yann.molard@univ-rennes1.fr

${ }^{b}$ Institute of Organic Chemistry, University of Stuttgart, Pfaffendwaldring 55, 70569, Stuttgart, Germany. E-mail: Sabine.Laschat@oc.uni-stuttgart.de $\dagger$ Electronic supplementary information (ESI) available: Experimental details, DSC traces, POM micrographs, SAXS and WAXS patterns, temperature dependent emission spectra, video of $\mathbf{C L}_{7}$ under irradiation alternatively in an air or inert atmosphere. See DOI: 10.1039/c5cc09110a
}

or chalcogen, $\mathrm{X}^{\mathrm{a}}=$ halogen or organic ligands are known for their phosphorescence with evidenced dual emission for $\mathrm{Cs}_{2} \mathrm{Mo}_{6} \mathrm{Br}_{14} \cdot{ }^{7}$ We recently developed three strategies to integrate these isotropic emitters in smectic or nematic and cholesteric LCs. ${ }^{8,9}$ However, up to now, a TMC containing CLC remains unknown. To design such self-assembling materials, we present herein a supramolecular approach in which the nanocluster alkali counter cations are complexed within the cavity of 18-crown-6 ether derivatives $\mathbf{C E}_{\boldsymbol{n}}$ that were previously used by some of us to design CLC (Scheme 1). ${ }^{10}$ Indeed, although the LC properties of $\mathbf{C E}_{\boldsymbol{n}}$ ligands and their respective complexes with monocharged species have been studied, ${ }^{11}$ we report for the first time the use and the influence of bulky polyionic inorganic species on the mesomorphic properties of $\mathbf{C E}_{\boldsymbol{n}}$ as well as the surprising influence of the supramolecular organization on the luminescence properties of hybrids.

The dibenzo[18]crown-6 derivatives $\mathbf{C E}_{\boldsymbol{n}}$ with two lateral tetraalkyloxy $o$-terphenyl units, as well as the $\mathrm{Cs}_{2} \mathrm{Mo}_{6} \mathrm{Br}_{14}$ cluster

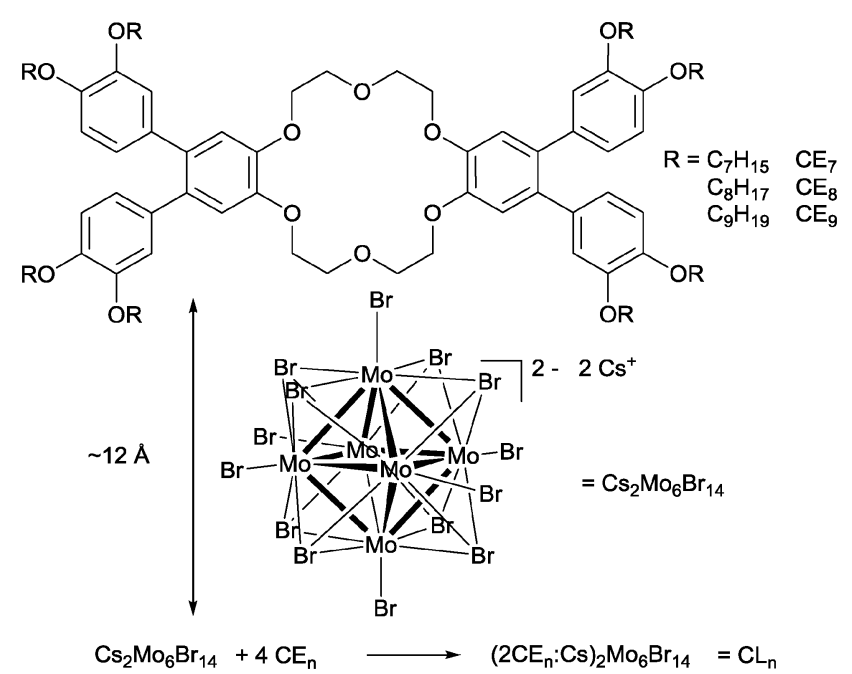

Scheme 1 Representation of $\mathrm{CE}_{n}$ ligands, $\mathrm{Cs}_{2} \mathrm{Mo}_{6} \mathrm{Br}_{14}$ and reaction leading to $\mathrm{CL}_{n}$ complexes. 
ternary salt, were prepared according to the reported procedure with conforming analytical data. ${ }^{10,12}$

This TMC salt was chosen for its high thermal stability, a prerequisite for developing new classes of clusters containing thermotropic hybrid materials. Complexes were obtained by mixing 1 equivalent of $\mathrm{Cs}_{2} \mathrm{Mo}_{6} \mathrm{Br}_{14}$ dissolved in acetone with 4 equivalents of $\mathbf{C E}_{\boldsymbol{n}}$ dissolved in dichloromethane. The reaction mixture was then stirred at $50{ }^{\circ} \mathrm{C}$ for 14 hours. After evaporation of solvents, the residue was taken up by dichloromethane to remove, by filtration through a microfilter, any traces of unreacted TMC, and heated under a high vacuum to yield the respective dry complexes $\left(2 \mathbf{C E}_{n}: \mathrm{Cs}\right)_{2} \mathrm{Mo}_{6} \mathrm{Br}_{14}=\mathbf{C L}_{\boldsymbol{n}}$. Their purity was verified by elemental analysis (ESI). ${ }^{1} \mathrm{H}$ NMR experiments performed on free $\mathbf{C E}_{\boldsymbol{n}}$ and their respective complexes $\mathbf{C L}_{\boldsymbol{n}}$ did not reveal many changes due to the $\mathrm{Cs}^{+}$complexation within the crown ether cavity (ESI, $\dagger$ Fig. S1 and S2). Only a slight upfield shift of signals corresponding to the methylene groups of the crown ring from $4.26 \mathrm{ppm}$ to $3.96 \mathrm{ppm}$ was observed upon complexation. This shift could be due to (1) a small decrease in the dihedral angle of the $\mathrm{OCH}_{2} \mathrm{CH}_{2} \mathrm{O}$ fragment upon ion complexation to accommodate the bulky $\mathrm{Cs}^{+}$cation and (2) an electric field caused by the presence of the salt. It is noteworthy that the complexation of smaller ions such as $\mathrm{K}^{+}$within the macrocyclic cavity induced the opposite effect. ${ }^{11}$ As previously observed, ${ }^{9}$ it is mandatory to maintain a $\mathrm{Cs}: \mathbf{C E}_{\boldsymbol{n}}$ ratio of $1: 2$ in order to maintain a full homogeneity of the cluster salt/ $\mathbf{C E}_{\boldsymbol{n}}$ complex.

The LC properties of hybrids were studied by polarized optical microscopy (POM), differential scanning calorimetry (DSC, ESI, $\dagger$ Fig. S4-S6) and, small and wide angle X-ray scattering (SAXS, WAXS, ESI, $\dagger$ Fig. S7-S14), the results of which are shown in Table 1. All complexes show enantiotropic LC phases extending over a wide temperature range. This behaviour largely contrasts with the native $\mathbf{C E}_{\boldsymbol{n}}$ precursor, for which LC phases were observed at lower temperatures and over narrower ranges. However, the increase in the mesophase stability as compared to the parent

Table 1 Thermodynamic and $\mathrm{X}$-ray diffraction data for $\mathrm{CL}_{n}$ compounds

\begin{tabular}{|c|c|c|c|c|c|}
\hline & Transition & $T /{ }^{\circ} \mathrm{C}$ & $\Delta C_{\mathrm{p}} / \Delta H$ & Mesophase & $\begin{array}{l}\text { Lattice } \\
\text { spacing/E }\end{array}$ \\
\hline $\mathrm{CL}_{9}$ & $\begin{array}{l}\mathrm{Cr} \rightarrow \mathrm{Col}_{\mathrm{r}} \\
\mathrm{Col}_{\mathrm{r}} \rightarrow \mathrm{I}\end{array}$ & $\begin{array}{l}129.8 \\
150.8(148.7)^{c}\end{array}$ & $\begin{array}{l}7.28^{b} \\
2.36^{b}\end{array}$ & $\begin{array}{l}\mathrm{Col}_{\mathrm{r}} \\
131{ }^{\circ} \mathrm{C} \\
p 2 m m\end{array}$ & $\begin{array}{l}a=66.3 \\
b=44.4 \\
h=4.0 \\
Z=1\end{array}$ \\
\hline $\mathbf{C L}_{8}$ & $\begin{array}{l}\mathrm{g} \rightarrow \mathrm{Col}_{\mathrm{r}} \\
\mathrm{Col}_{\mathrm{r}} \rightarrow \mathrm{Col}_{\mathrm{h}} \\
\mathrm{Col}_{\mathrm{h}} \rightarrow \mathrm{I}\end{array}$ & $\begin{array}{l}91.6 \\
146.6 \\
164.4(162.2)^{c}\end{array}$ & $\begin{array}{l}0.43^{a} \\
2.54^{b} \\
2.50^{b}\end{array}$ & $\begin{array}{l}\mathrm{Col}_{\mathrm{r}} \\
119{ }^{\circ} \mathrm{C} \\
p 2 m m \\
\mathrm{Col}_{\mathrm{h}} \\
150{ }^{\circ} \mathrm{C} \\
p 6 m m\end{array}$ & $\begin{aligned} a & =62.5 \\
b & =43.8 \\
h & =4.5 \\
Z & =1 \\
a & =35.5 \\
h & =4.5 \\
Z & =1\end{aligned}$ \\
\hline $\mathbf{C L}_{7}$ & $\begin{array}{l}\mathrm{g} \rightarrow \mathrm{Col}_{\mathrm{r}} \\
\mathrm{Col}_{\mathrm{r}} \rightarrow \mathrm{I}\end{array}$ & $\begin{array}{l}96.8(96.9) \\
159.2(147.9)^{c}\end{array}$ & $\begin{array}{l}0.141^{a} \\
2.19^{b}\end{array}$ & $\begin{array}{l}\mathrm{Col}_{\mathrm{r}} \\
127^{\circ} \mathrm{C} \\
p 2 m m\end{array}$ & $\begin{aligned} a & =63.1 \\
b & =43.0 \\
h & =4.4 \\
Z & =1\end{aligned}$ \\
\hline
\end{tabular}

${ }^{a}$ In $\mathrm{kJ} \mathrm{mol}^{-1} \mathrm{~K}^{-1} \cdot{ }^{b}$ In $\mathrm{kJ} \mathrm{mol}{ }^{-1} \cdot{ }^{c}$ Observed on cooling from the isotropic state; Cr: crystalline state; $\mathrm{Col}_{\mathrm{r}}$ : columnar rectangular; $\mathrm{Col}_{\mathrm{h}}$ : columnar hexagonal; I: isotropic state.

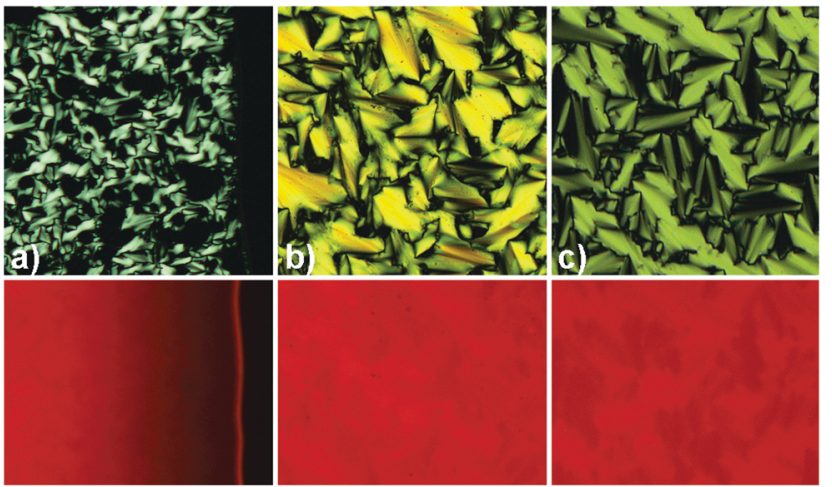

Fig. 1 Polarized Optical Micrographs of (a) $\mathrm{CL}_{9}\left(T=150{ }^{\circ} \mathrm{C}\right)$, (b) $\mathrm{CL}_{8}$ ( $\left.T=163{ }^{\circ} \mathrm{C}\right)$ and (c) $\mathrm{CL}_{7}\left(T=150^{\circ} \mathrm{C}\right)$ under white light (top) and UV irradiation (bottom)

$\mathbf{C E}_{\boldsymbol{n}}$ precursor is similar to that encountered when soft anions such as iodide or bridging anions such as hexafluorophosphate or thiocyanate are used to counterbalance the positive charge of a potassium cation embedded within the crown cavity. ${ }^{11}$ This unexpected result is of particular interest as host-guest complexes between the small 18-crown-6 cavity and the sterically demanding $\mathrm{Cs}^{+}$cation are usually supposed to be weak. It could eventually be attributed to the polyionic character of the TMC salt and the strong interactions existing between the complexed $\mathrm{Cs}^{+}$and $\left[\mathrm{Mo}_{6} \mathrm{Br}_{14}\right]^{2-}$ dianion which insure a better stability of the supramolecular assemblies upon heating. Surprisingly, the DSC thermogram of $\mathbf{C L}_{\mathbf{8}}$ reveals, upon heating, the formation of two LC phases, whereas upon cooling, only one first order transition corresponding to the isotropic-to-LC phase transition is observed (ESI, $\dagger$ Fig. S5). Fig. 1 shows the optical fan-shaped focal conic textures observed upon cooling for all samples, which are typical indicators of columnar mesophases. Heating $\mathbf{C L}_{\mathbf{8}}$ from $100{ }^{\circ} \mathrm{C}$ up to $160{ }^{\circ} \mathrm{C}$ did not lead to any noticeable change in the observed textures. Irradiating the samples with UV light illustrates their excellent homogeneity thanks to the well-known red NIR emission of TMC (vide infra). The same experiments performed at $200{ }^{\circ} \mathrm{C}$ also reveal a very good homogeneity showing that the interactions between the crown centre and $\mathrm{Cs}^{+}$cations are strong enough to maintain the integrity of the complex even at very high temperatures (ESI, $\dagger$ Fig. S3).

SAXS and WAXS patterns recorded at $127{ }^{\circ} \mathrm{C}, 119{ }^{\circ} \mathrm{C}$ and $131{ }^{\circ} \mathbf{C}$ for $\mathbf{C L}_{7}, \mathbf{C L}_{\mathbf{8}}$ and $\mathbf{C L}_{\mathbf{9}}$ respectively, contained sharp and intense reflections in the small angle region. We first analysed the XRD data, to investigate possible lamello-columnar packing, examples of which were independently reported by Donnio, Ziessel and Marcelis for metallomesogens, ${ }^{13}$ donor-acceptortriads, ${ }^{14}$ side-chain LC polymers ${ }^{15}$ or triazines with pendant triphenylenes. ${ }^{16}$ We first checked whether sharp Bragg reflections indicating a smectic order were present for complexes $\mathbf{C L}_{\boldsymbol{n}}$. However, neither characteristic layer reflections in the SAXS diffractogram nor the second halo in the wide angle region were visible. Thus, a lamello-columnar phase or a coexisting lamellar and columnar packing could be ruled out.

Hence, the indexation of observed patterns allowed the identification of a rectangular columnar phase with $p 2 \mathrm{~mm}$ symmetry 
for the three complexes (see Tables S1-S4, ESI, $\dagger$ for a full indexation). All WAXS patterns contained a broad and large signal around $4.4 \AA$ arising from the fluid-like behaviour of the molten alkyl chains and from the stacking of the aromatic units within the columns confirming the liquid crystalline nature of all complexes. For $\mathbf{C L}_{\mathbf{8}}$, additional measurements were performed at $150{ }^{\circ} \mathrm{C}$ to characterize the unexpected second mesophase detected via DSC upon heating. Three signals with reciprocal $d$-spacings in the ratio $1: 1 / \sqrt{ } 3: 1 / 2$ were observed in the SAXS pattern and are in good accordance with the formation of a $2 \mathrm{D}$ hexagonal lattice with a $p 6 \mathrm{~mm}$ symmetry $\left(\mathrm{Col}_{h}\right)$. In this case, the unit cell parameter $(a=35.5 \AA)$ was calculated by looking at the position of the most intense scattering signal assigned to the (10) reflection. A comparison of previously published XRD data for metal-free crown ether $\mathbf{C E}_{\mathbf{1 1}}{ }^{17}$ with those for $\mathbf{C L}_{\boldsymbol{n}}$ (Table 1) revealed that the symmetry of the $\mathrm{Col}_{\mathrm{r}}$ lattice changed upon complexation. While the lattice parameter $a$ remains relatively unaffected, i.e. $66.1 \AA\left(\mathbf{C E}_{\mathbf{1 1}}\right)$ vs. $66.3 \AA\left(\mathbf{C L}_{\mathbf{9}}\right)$ despite the difference of $2 \mathrm{CH}_{2}$ units in the side chain, the $b$ values almost doubled from $25.1 \AA\left(\mathbf{C E}_{\mathbf{1 1}}\right)$ to $44.4 \AA\left(\mathbf{C L}_{\mathbf{9}}\right)$. Halos were in a similar range ( $4.6 \AA$ ㅇ vs. $4.0 \AA$ ). To rationalize these results, we propose that the nanocluster, because of its bulkiness, cannot be accommodated within the $c 2 \mathrm{~mm}$ lattice of $\mathbf{C E}_{\boldsymbol{n}}$, resulting in a $p 2 \mathrm{~mm}$ lattice with an elongated $b$ axis, so that the cluster fits in the centre of the unit cell and is surrounded by 4 stacks of crown ethers $\mathbf{C E}_{\mathbf{9}}$ with an intracolumnar distance of $4 \AA$ A (Fig. 2). This results in a height of $12 \AA$ for the unit cell and the $(1: 4)$ cluster/CE $\mathbf{C E}_{\mathbf{9}}$ stoichiometry is maintained. In that case the inorganic moieties volumic fraction is around 9 vol\%. For the corresponding $\mathrm{Col}_{\mathrm{h}}$ phase of $\mathbf{C L}_{\mathbf{8}}$, the observed $a$ value should allow a hexagonal packing of the discotic crowns $\mathbf{C E}_{\mathbf{8}}$, while each $\mathrm{Mo}_{6} \mathrm{Br}_{14}{ }^{2-}$ unit is encapsulated by three crowns and leads to a volumic fraction of $22 \mathrm{vol} \%$ for $\mathrm{Cs}_{2} \mathrm{Mo}_{6} \mathrm{Br}_{14}$.

As expected, the emission properties of $\left[\mathrm{Mo}_{6} \mathrm{Br}_{14}\right]^{2-}$ are retained within the hybrid materials (see ESI, $\dagger$ Fig. S15). ${ }^{18}$
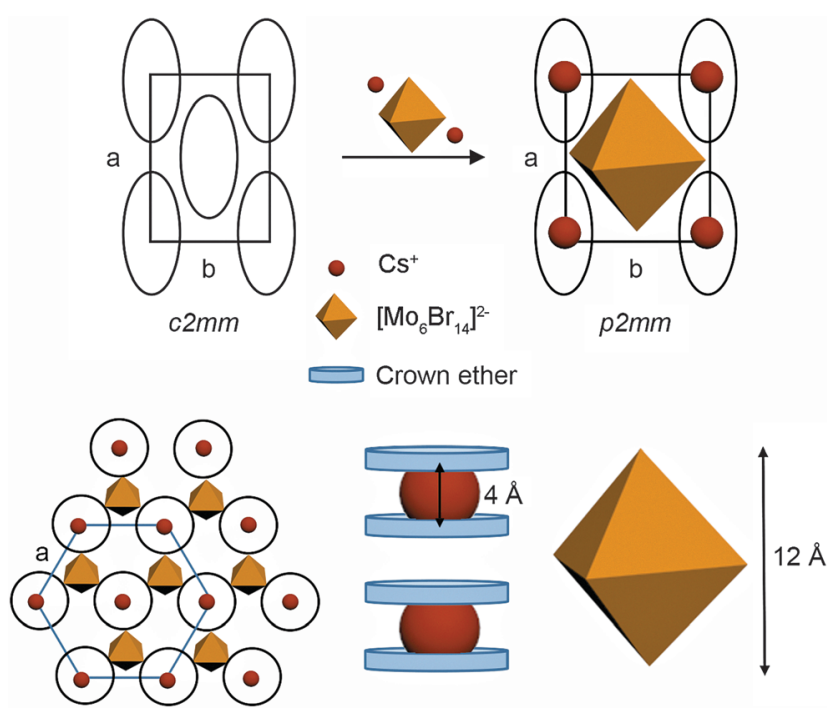

Fig. 2 Proposed packing models of $\mathrm{CL}_{n}$ compounds in the $\mathrm{Col}_{r}$ (top, $n=7-9$ ) and Coln (bottom, $n=8$ ) mesophase.
The photoluminescence spectra $\left(\lambda_{\text {exc }}=380 \mathrm{~nm}\right)$ show a broad and intense band extending from $550 \mathrm{~nm}$ up to $950 \mathrm{~nm}$. The influence of the hybrid nanostructures on the inorganic emitter emission was investigated by temperature-dependent luminescence studies. Samples were heated up to the isotropic state and slowly cooled to reach a nanostructured glassy or crystalline state at $25{ }^{\circ} \mathrm{C}$ prior to measurements. The phosphorescence signals were collected at every degree upon heating (see the ESI, $\dagger$ Fig. S16 and S17). As previously reported, ${ }^{19}$ if the emission intensity variation upon heating is only due to an increase of non-radiative deactivation processes, it should follow an exponential law of the type: $I(T)=I_{0} \exp (-A / T)$ where $A$ is constant and $I_{0}$ the emission intensity at a given temperature. Thus, reporting $\ln \left(I / I_{300}\right)=f(1 / T)$ should give a straight line and this is what is observed for $\mathrm{Cs}_{2} \mathrm{Mo}_{6} \mathrm{Br}_{14}$ (Fig. 3). Surprisingly, increasing the temperature from $25{ }^{\circ} \mathrm{C}$ up to $140{ }^{\circ} \mathrm{C}$ does not have much effect on the ability of the hybrid materials to emit light as an emission intensity loss of only less than $10 \%$ was recorded (the intensity loss at $140{ }^{\circ} \mathrm{C}$ is about $77 \%$ for $\mathrm{Cs}_{2} \mathrm{Mo}_{6} \mathrm{Br}_{14}$ in its powder form). At higher temperatures, the obtained curves significantly deviate from the straight line with a similar behaviour for $\mathbf{C L}_{\mathbf{7}}$ and $\mathbf{C} \mathbf{L}_{\mathbf{9}}$. The separation of the clusters from each other by isolating triangular arrays of crown ethers might be the reason for the increased luminescence intensity of $\mathbf{C L}_{\mathbf{8}}$ in the high temperature $\mathrm{Col}_{\mathrm{h}}$ phase as compared to the low temperature $\mathrm{Col}_{\mathrm{r}}$ phase. Presumably, the crown ethers act as an isolating matrix for luminescent clusters, making these hybrids attractive alternatives with regards to polymers for applications requiring temperatures around $100{ }^{\circ} \mathrm{C}$. ${ }^{20}$ Thus, the columnar nanostructures have a strong influence on the emissive ability of hybrids despite the isotropic nature of the inorganic emitter. Let us emphasize that such unprecedented high stability of the emission intensity vs. temperature is particularly rare and has never been reported so far for TMC or TMC-containing hybrid materials.

As illustrated by absolute quantum yield measurements performed in an air or $\mathrm{N}_{2}$ atmosphere, the emission intensity can also

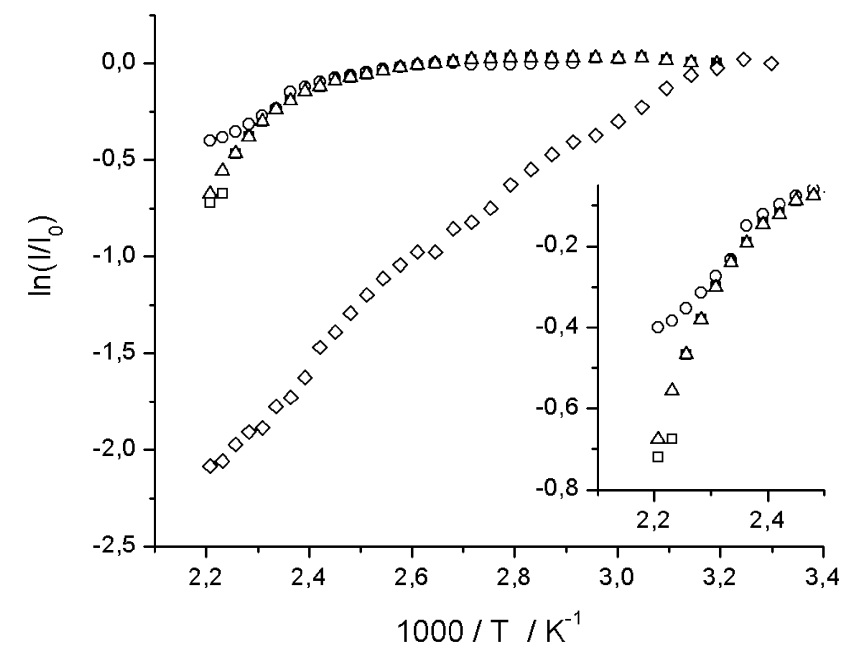

Fig. 3 Evolution of luminescence intensity at $700 \mathrm{~nm}$ with temperature for $\mathrm{Cs}_{2} \mathrm{Mo}_{6} \mathrm{Br}_{14}$ (diamond), $\mathrm{CL}_{9}$ (triangle), $\mathrm{CL}_{8}$ (circle) and $\mathrm{CL}_{7}$ (square). Inset: Zoom of the high temperature area for hybrids. 
be modulated by modifying the local atmosphere of the material. In all cases, a reversible and instantaneous switch from 0.05 or 0.07 in air up to $0.20,0.26$ or 0.30 in an $\mathrm{N}_{2}$ atmosphere was measured for $\mathbf{C L}_{\mathbf{7}}, \mathbf{C L}_{\mathbf{8}}$ and $\mathbf{C L}_{\mathbf{9}}$, respectively (Fig. S18 and Video S1, $\mathrm{ESI} \dagger$ ). This phenomenon, which shows that these materials might be used as efficient oxygen sensors, is due to the $\mathrm{O}_{2}$ permeability of $\mathbf{C L}_{\boldsymbol{n}}$ and is based on the ability of the excited states of the phosphorescent metal clusters to be quenched by molecular triplet oxygen, thus creating singlet oxygen. ${ }^{21}$ Although we demonstrated recently the same effect when nanoclusters are introduced into gas-permeable polymer matrices, ${ }^{22}$ this is the first time that such behaviour is reported in a liquid crystalline material.

In conclusion, we show herein, that nanometric luminescent transition metal cluster compounds are easily integrated in a CLC hybrid material by using a supramolecular approach. In these materials, $\mathrm{Cs}^{+}$cluster unit counter cations are complexed within the cavity of crown ether derivatives functionalized by $o$-terphenyl units that are well known to generate columnar liquid crystalline phases. We show that the introduction of cluster salts results in columnar rectangular phases of $p 2 \mathrm{~mm}$ symmetry and that their thermal stability is largely enhanced as compared to the parent crown ether $\mathbf{C E}_{\boldsymbol{n}}$. Surprisingly, a second columnar hexagonal phase was observed on heating for $\mathbf{C L}_{\mathbf{8}}$. Luminescence studies reveal that the red NIR clusters emission stability upon heating is unexpectedly largely enhanced as compared to its precursor namely $\mathrm{Cs}_{2} \mathrm{Mo}_{6} \mathrm{Br}_{14}$. Moreover, we demonstrate for the first time that modifying the atmosphere surrounding the LC hybrids with an inert gas induces a large, instantaneous and reversible increase of its emission efficiency thanks to the good $\mathrm{O}_{2}$ permeability of the LC matrix. The columnar mesophases observed for these novel clustomesogens in combination with their luminescence properties make them promising candidates for oxygen sensors, optoelectronic or photovoltaic devices. As a further step towards such applications, the mesophase temperature ranges need to be lowered by molecular design. Work towards this goal is currently in progress.

This work has been done in the frame of the ANR Clustomesogen: ANR-13-BS07-0003-01 and a Marie Curie International Incoming Fellowship within the 7th European Community Framework Program. Both organizations are gratefully acknowledged. The authors also wish to thank Dr F. Camerel for DSC access and the Fonds der Chemischen Industrie (Kekulé fellowship for S. B.) for generous financial support.

\section{References}

1 S. Chandrasekhar, B. K. Sadashiva and K. A. Suresh, Pramana, 1977, 9, 471-480.

2 J. W. Goodby, P. J. Collings, T. Kato, C. Tschierske, H. F. Gleeson and P. Raynes, Handbook of Liquid Crystals: Applications of Liquid Crystals, Wiley-VCH Verlag GmbH \& Co. KGaA, 2nd edn, 2014, vol. 8.
3 S. Kumar and V. Lakshminarayanan, Chem. Commun., 2004, $1600-1601$.

4 X. Feng, L. Sosa-Vargas, S. Umadevi, T. Mori, Y. Shimizu and T. Hegmann, Adv. Funct. Mater., 2015, 25, 1180-1192.

5 S. Kumar and L. K. Sagar, Chem. Commun., 2011, 47, 12182-12184; M. Kumar and S. Kumar, $R S C A d v$., 2015, 5, 1262-1267.

6 F. A. Cotton, Inorg. Chem., 1964, 3, 1217-1220.

7 T. G. Gray, C. M. Rudzinski, D. G. Nocera and R. H. Holm, Inorg. Chem., 1999, 38, 5932-5933; A. W. Maverick and H. B. Gray, J. Am. Chem. Soc., 1981, 103, 1298-1300; K. Costuas, A. Garreau, A. Bulou, B. Fontaine, J. Cuny, R. Gautier, M. Mortier, Y. Molard, J.-L. Duvail, E. Faulques and S. Cordier, Phys. Chem. Chem. Phys., 2015, 17, 28574-28585.

8 M. Prevot, M. Amela-Cortes, S. k. Manna, S. Cordier, T. Roisnel, H. Folliot, L. Dupont and Y. Molard, J. Mater. Chem. C, 2015, 3, 5152-5161; S. M. Wood, M. Prévôt, M. Amela-Cortes, S. Cordier, S. J. Elston, Y. Molard and S. M. Morris, Adv. Opt. Mater., 2015, 3, 1368-1372; Y. Molard, A. Ledneva, M. Amela-Cortes, V. Circu, N. G. Naumov, C. Meriadec, F. Artzner and S. Cordier, Chem. Mater., 2011, 23, 5122-5130; Y. Molard, F. Dorson, V. Circu, T. Roisnel, F. Artzner and S. Cordier, Angew. Chem., Int. Ed., 2010, 49, 3351-3355.

9 S. K. Nayak, M. Amela-Cortes, C. Roiland, S. Cordier and Y. Molard, Chem. Commun., 2015, 51, 3774-3777.

10 A. Schultz, S. Laschat, A. Saipa, F. Giesselmann, M. Nimtz, J. L. Schulte, A. Baro and B. Miehlich, Adv. Funct. Mater., 2004, 14, 163-168.

11 M. Kaller, S. Tussetschlaeger, P. Fischer, C. Deck, A. Baro, F. Giesselmann and S. Laschat, Chem. - Eur. J., 2009, 15, 9530-9542.

12 K. Kirakci, S. Cordier and C. Perrin, Z. Anorg. Allg. Chem., 2005, 631, 411-416.

13 M. Stepien, B. Donnio and J. L. Sessler, Chem. - Eur. J., 2007, 13, 6853-6863; T. Cardinaels, K. Driesen, T. N. Parac-Vogt, B. Heinrich, C. Bourgogne, D. Guillon, B. Donnio and K. Binnemans, Chem. Mater., 2005, 17, 6589-6598; R. Ziessel, L. Douce, A. El-Ghayoury, A. Harriman and A. Skoulios, Angew. Chem., Int. Ed., 2000, 39, 1489-1493; A. El-Ghayoury, L. Douce, A. Skoulios and R. Ziessel, Angew. Chem., Int. Ed., 1998, 37, 1255-1258.

14 K.-Q. Zhao, L.-L. An, X.-B. Zhang, W.-H. Yu, P. Hu, B.-Q. Wang, J. Xu, Q.-D. Zeng, H. Monobe, Y. Shimizu, B. Heinrich and B. Donnio, Chem. - Eur. J., 2015, 21, 10379-10390.

15 I. Tahar-Djebbar, F. Nekelson, B. Heinrich, B. Donnio, D. Guillon, D. Kreher, F. Mathevet and A.-J. Attias, Chem. Mater., 2011, 23, 4653-4656.

16 C. P. Umesh, A. T. M. Marcelis and H. Zuilhof, Liq. Cryst., 2015, 42, $1450-1459$.

17 M. Kaller, C. Deck, A. Meister, G. Hause, A. Baro and S. Laschat, Chem. - Eur. J., 2010, 16, 6326-6337.

18 S. Cordier, Y. Molard, K. A. Brylev, Y. V. Mironov, F. Grasset, B. Fabre and N. G. Naumov, J. Cluster Sci., 2015, 26, 53-81; S. Cordier, F. Grasset, Y. Molard, M. Amela-Cortes, R. Boukherroub, S. Ravaine, M. Mortier, N. Ohashi, N. Saito and H. Haneda, J. Inorg. Organomet. Polym. Mater., 2015, 25, 189-204; M. Amela-Cortes, A. Garreau, S. Cordier, E. Faulques, J.-L. Duvail and Y. Molard, J. Mater. Chem. C, 2014, 2, 1545-1552.

19 S. Suarez, O. Mamula, D. Imbert, C. Piguet and J. C. G. Bunzli, Chem. Commun., 2003, 1226-1227.

20 M. Shi, Y. Guan, J. Zhang and X. Wang, RSC Adv., 2015, 5, 34900-34907.

21 J. A. Jackson, M. D. Newsham, C. Worsham and D. G. Nocera, Chem. Mater., 1996, 8, 558-564; J. A. Jackson, C. Turro, M. D. Newsham and D. G. Nocera, J. Phys. Chem., 1990, 94, 4500-4507.

22 M. Amela-Cortes, S. Paofai, S. Cordier, H. Folliot and Y. Molard, Chem. Commun., 2015, 51, 8177-8180. 